\section{Adult Colorectal Invagination Associated with Colonic Cancer and Established by Fiberscopy of the Sigmoid Colon}

Intestinal intussusception is a rare occurrence in adults, and is usually difficult to diagnose. The history often runs over a long period, sometimes more than a year. Intussusception of the colon is usually associated with a primary malignant tumor, and the true cause of the condition is always diagnosed during surgery. The diagnosis of intussusception can sometimes be established using computed tomography (1). We report here on a case of colorectal intussusception diagnosed preoperatively using fiberscopy of the sigmoid colon.

A 54-year-old woman was admitted to our hospital on an emergency basis after the development of lower abdominal pain and anal bleeding. A plain abdominal radiograph showed a colon gas cut-off on the anal side of the transverse colon. On digital examination, the overlapping intestine was palpable at $6-7 \mathrm{~cm}$ from the anal verge. After the digital examination, fiberscopy of the colon revealed double lumina in the rectum. The invaginated lumen was reddish and edematous. However, no tumor could be detected (Figure 1). A barium enema showed a clawlike finding, without filling, on the oral side (Figure 2). An emergency laparotomy was performed, and a tumor-induced colorectal invagination was identified. The invaginated area was approximately $20 \mathrm{~cm}$ in length from the tumor. A left hemicolectomy and localized lymph-node dissection were carried out. The resected specimen showed a large, protruding cancer measuring $6.0 \times 6.0 \mathrm{~cm}$. At pathology, the tumor was found to be a welldifferentiated adenocarcinoma invading the submucosal layer, without lymph-node metastasis. The postoperative course was uneventful.

The specific clinical features of this case of intussusception, established preoperatively by fiberscopy of the sigmoid colon, have been described in the literature very rarely. The importance of the clinical picture in targeting preoperative instrumental investigations should be emphasized.

H. Kimura', K. Yabushita', A. Tsuneda!, K. Tazawa!, T. Inoue', M. Earashi', K. Maeda', Y. Kuroda', K. Konishi', M. Tsuji ', A. Miwa

Dept. of Surgery, Toyama Prefectural Center Hospital, Toyama, Japan

2Dept. of Pathology, Toyama Prefectural Center Hospital, Toyama, Japan

\section{References}

1. Wallner B, Friedrich JM, Oettinger W. Colorectal invagination in adults following removal of a sigmoid polyp. Röntgenblätter 1990; $43: 78-9$

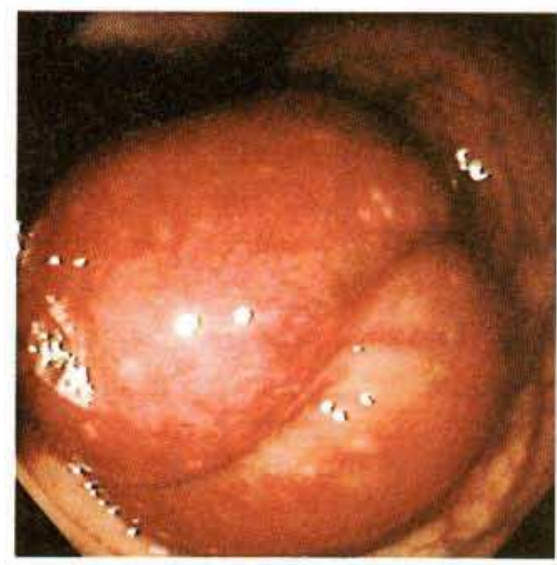

Figure 1: Fiberscopy of the colon, showing double lumina in the rectum.

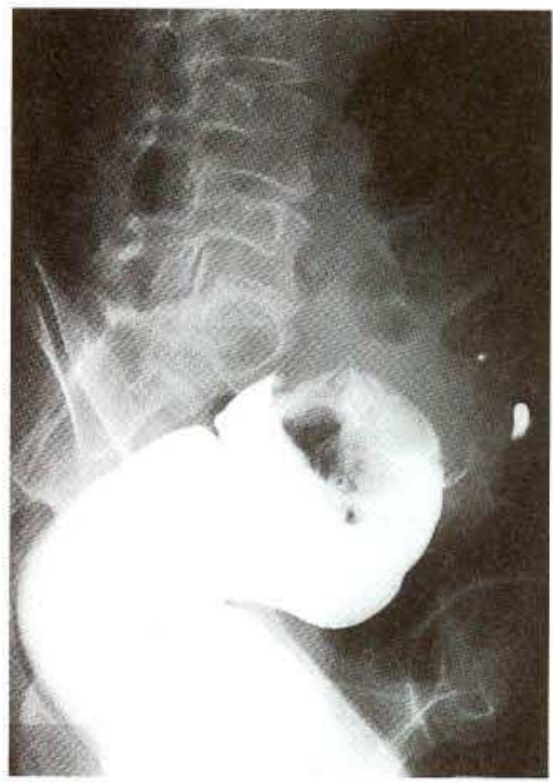

Figure 2: Barium enema, showing a clawlike finding in the rectum.

Corresponding Author

H. Kimura, M. D.

Dept. of Surgery

Toyama Prefectural Center Hospital 2-2-78, Nishinagac

Toyama 930

Japan

Fax: $+81-764-22-0667$ 